\title{
DESIGNING OF DRIVER BEHAVIOR MODEL AND ITS DATA ANALYSIS FOR VEHICULAR APPLICATIONS
}

\author{
Pankaj H. Chandankhede ${ }^{1}$, Milind M. Khanapurkar ${ }^{2}$ \\ ${ }^{1}$ Research Scholar, Department of Electronics Engineering, GHRCE, Nagpur, Maharashtra, India \\ ${ }^{2}$ Professor \& Head, Department of Electronics and Telecommunication Engineering, GHRCE, Nagpur, Maharashtra, \\ India
}

\begin{abstract}
"Design and Implementation of Evidence Collection System from Event Data Recorder", deals with collection of Evidence for accident analysis. These evidences are in form of graphs. It includes graph of Speed Vs Time, Engine Temperature Vs Time, Distance Vs Time, Brake Pressure Vs Time, Engine Speed (RPM) Vs Time, Impact Vs Time and Tire Pressure Vs Time. Also it provides single graph merged with all these parameters at the time of accident. One more advantage of system is that, it can also provide Driver Behavior Model. By using this, driver's driving performance could be found out. This system is nothing but the GUI constructed using Microsoft Visual Studio. All graphs are plotted using this Graphical User Interface. For Data Analysis purpose, B-tree algorithm is used here. Its performance for secondary storage devices and huge data handling capacity makes it more efficient. Data recorded by Event Data Recorder is used here as input. Event Data Recorder is also called as Black box of vehicles. It records vehicular data like speed, date, time, location (latitude, longitude), alcohol content of driver, airbag deployment etc. This data plays an important role detection and analysis of accident if any persists. These EDR are controlled by processors for very accurate operations.
\end{abstract}

Keywords: Event Data Recorder, Evidence Collection System \& Data analysis

\section{INTRODUCTION}

Design of Evidence Collection System from Event Data Recorder is proposed here. This system plays most important role in case of car crash analysis. Nowadays car crash analysis needs physical evidences including clear evidences. These clear evidences consists Eye witness and trace marks of vehicle etc. Following figure 1 depicts current evidence collection system.

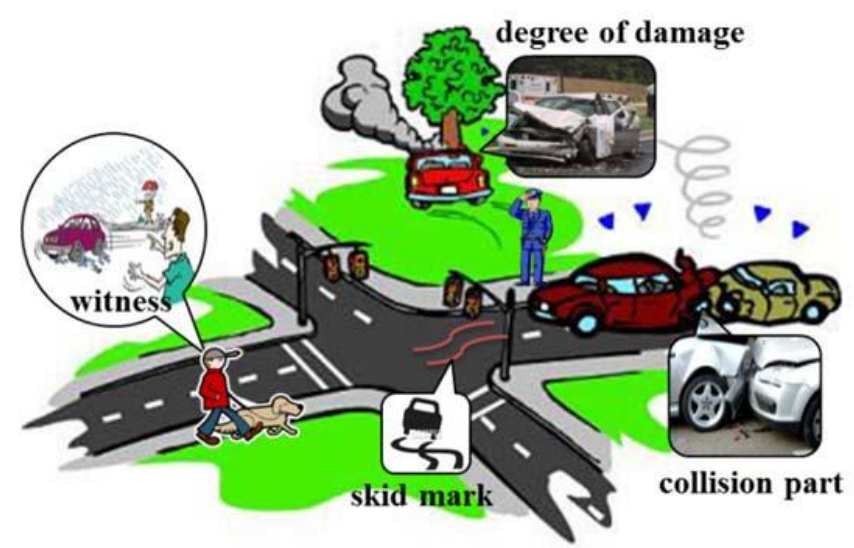

Fig - 1: Currently using methods for analysis of vehicle accidents

One may get confused by visiting such accident site. For correct analysis of accident site, cops must see for all these evidences. Often, there is situation of insufficient proofs. Most of the times it may also possible that some clues got missed by police or police reached accident site by too late and till then evidences got vanished. This is very time consuming and complex process. By using this evidence collection system we could find cause of accident cases just from police station. This reduces manpower, time and complexity over traditional system. This system's results could be used very effectively in areas like [1]:

- Crash investigation

- Evidence collection

- Driver monitoring and training

- Safety purpose

- Insurance purpose

- Driving license issuing case

\section{SYSTEM DESIGN}

Currently it's much difficult to find out reason of accident. By guessing only surrounding of accident site accident analysis could be done. Rarely there are cases where eye witness is present. And these eye witnesses are also quit shy in nature or they are afraid about police cases. Due to behavior of police authorities people are rarely stand up as accident witness. For such situation, this Evidence collection system is too much helpful. Here, data recorded by event data recorder is analyzed through all aspects and actual cause of accident is detected [6].

This evidence collection systems reports could be presented in court as a proof and real culprit will be arrested [11]. It is also need to find out, whose mistake is responsible for an accident. By checking data of Distance (Distance between our vehicle and next vehicle/ obstacle), applied Brake Pressure, Speed guilty one can be caught. When someone is 
driving by high speed, then driver must need to apply hard brakes at critical case. This speed will be recorded by Event Data Recorder and subsequently shown in GUI. By finding applied brake pressure value, severity of accident can be found out. Also, when vehicle got crash impact sensor will also measure value of impact. Obviously for major accident, this sensor's reading will be high. All of these values will be in opposing of criminal [7].
Driver behavior model will show incidents where driver had crossed speed threshold limit. This speed threshold limit will play an important role for minimizing accidents due to high speed. Due to fear that, vehicle is recording whatever speed we are driving, vehicle drivers will drive in limit and accidents due to high speeds will be reduced. Such model is very useful in car rent services or public transport services. Transport company owner could analyze his driver behavior by this facility[5].

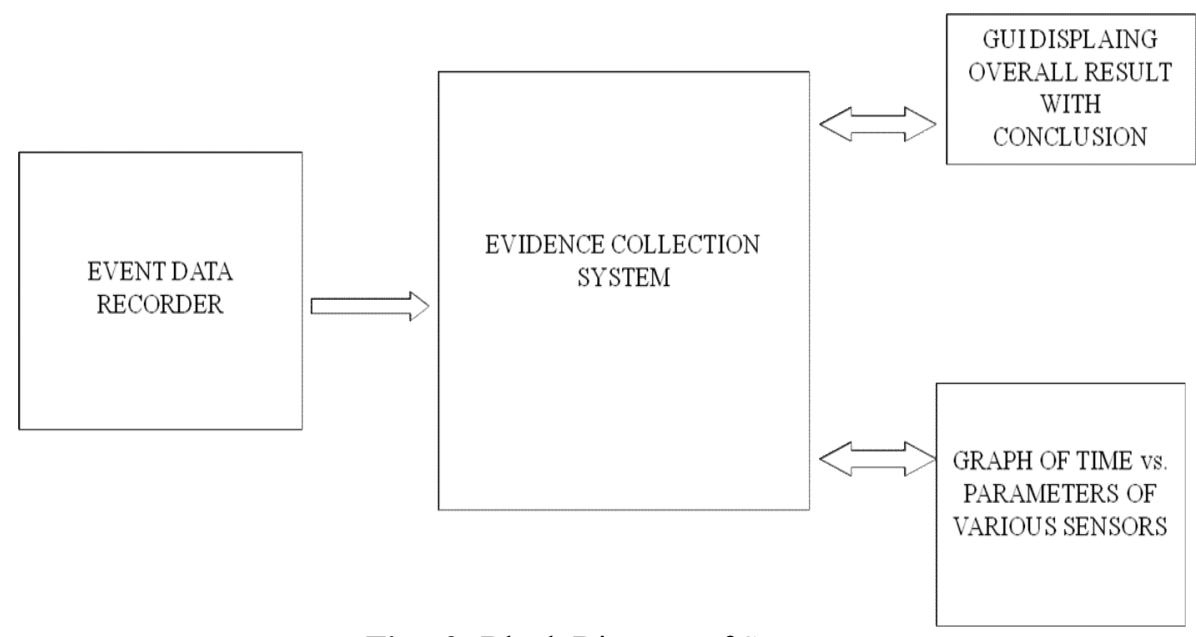

Fig - 2: Block Diagram of System

Block by block working of system illustrated in figure 2 . Each block of this diagram plays an important role for proper working of system.

Event Data Recorder: This Event Data Recorder is also called as Car Black Box. It is most important device which could be used to store vehicle data. It has sensors mounted on vehicle [4]. Event data Recorder to be used here has Accelerometer for speed measurement, Pressure sensor for Brake Pressure, Tire Pressure and Impact Measurement, GPS for location determination and Temperature measurement sensor to measure Engine Temperature [2]. All of this data recorded by Event Data Recorder is used by Evidence Collection System. Data from EDR is made available for secondary storage devices (E.g. Pen Drive).

Evidence Collection System: It receives data from Event Data Recorder and processes it. It maps data of Excel sheet into GUI. Due to this, whenever we fire a query (Demand for result) data access time reduces and results got in short time. From processing of all this data evidences for accident could be obtained and main motto of system will be satisfied. These evidences may be in form of speed of vehicle, Engine Temperature, Location of Vehicle, Impact of the crash or any other like this [3].

Graphical User Interface (GUI): This is actual human interface window. User can input data here to obtain particular results. Particular date and Time could be fed up to get results of that instant. But that information must be available in data base. Driver behavior model could be constructed by just feeding date and time. Accident message also be displayed by a single click.

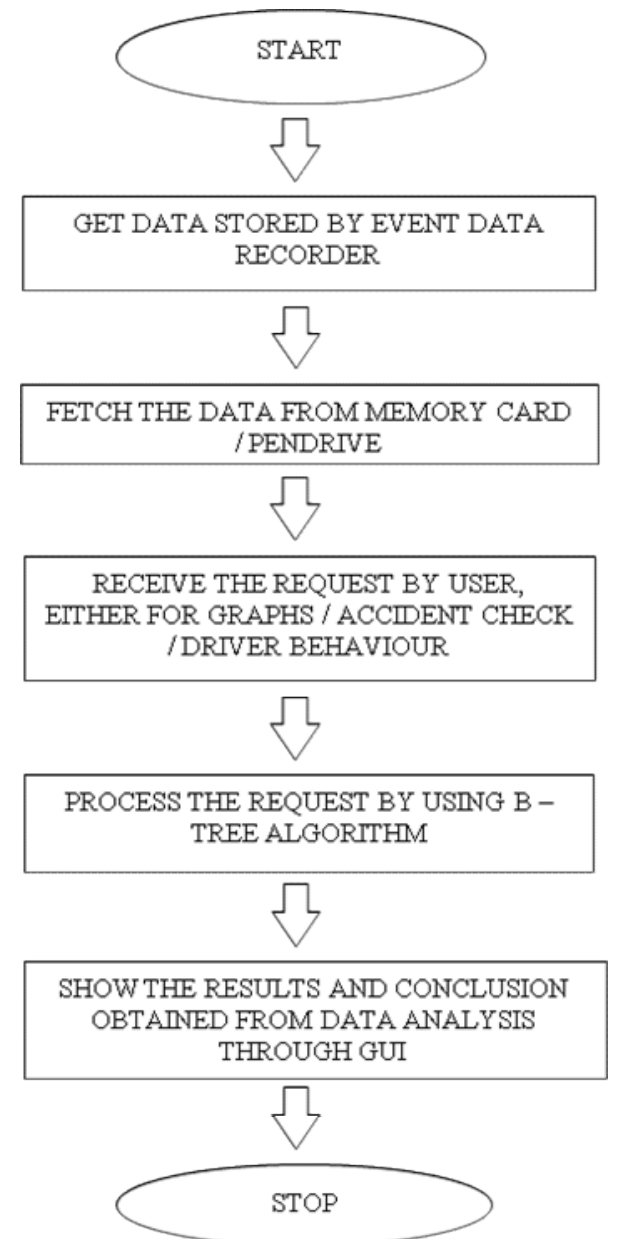

Fig-3. Flowchart of System 
As shown in figure 3, first stage is start. Here we initialize Evidence Collection System opens GUI, attach Pen Drive of Excel sheet. By this Evidence Collection System first gets data of EDR. This data is nothing but sensors readings at the time of vehicle driving. It consists speed of vehicle, Tire pressure of vehicle, vehicle Location in form of Latitude and Longitude, Brake pressure whenever applied, Engine speed in RPM, Alcohol content of driver and like this. This all data is stored in form of excel sheet. Question of why excel sheet is explained later on. In data processing phase, Evidence Collection System fetches all this information from Secondary storage devices like pen drive and brought up in Graphical User Interface (GUI) [8].

Data processing results are made available at this third stage. Column by column and row by row data of input excel sheet is shown on GUI. If one wants to analyze data manually then this can be done here. Excel sheet of whatever size will be uploaded here. Yes, time required to upload excel file may be vary depending on file size.

When we demand for graph of particular parameter, then this will be shown in results section. Graphs of different parameters, Driver behavior Model and Accident analysis message are falls in this results section. This Accident analysis message may also called as conclusion of system. Then at stop, we are with print copies of Accident analysis result which can be produced in court as a proof.

\section{DESIGN \& IMPLEMENTATION}

\subsection{B Tree Technique}

$\mathrm{B}$ tree is renowned searching technique based on tree structure. This B stands for Balanced Tree. It is invented by Rudolf Buyer and Ed McCreight in 1971 at Boeing Research Labs. Many new researches took place by then, but basic idea and internal structure of B tree is still same. In $B$ tree non-leaf nodes can have different number of child nodes. Each node of B tree has some number of keys. These keys divide whole tree into sub-trees. The main advantage of B tree is that it has balanced structure throughout. Means all of the leaves of structure are at same distance from root. Every leaf will be at equal level from root. This plays an important role in working of B tree. While execution of B tree algorithm time require fetching each node is small and same. And nowadays system with less time complexity is in demand[9].

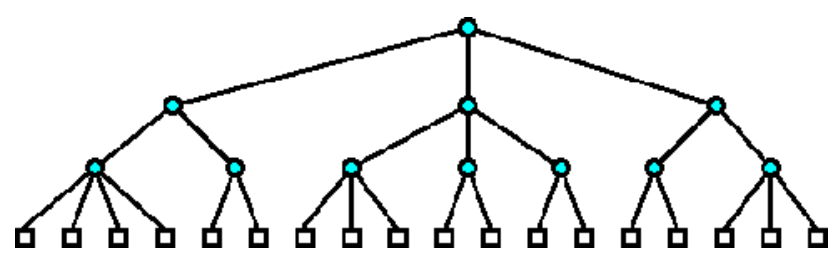

Fig. 4-Example of B Tree

The figure 4 shows example of B tree. We can see here, the one at top most is a root and other in circular shape are called as inter nodes. Square shaped objects at last level are called as leaves. Actual data is stored in inter nodes and leaves. After connecting together roots, inter-nodes and leaves, a tree like structure creates. That's why it is called as B Tree. From example it's clear that each leave is at same distance from root and is at fourth level [10].

Above figure 5.shows flow of B- tree algorithm. How B tree search works in this system is explained here. It starts when we fire a query i.e. when we put up a search request. This search request may be graph of any parameter or Driver behavior model or could be Accident detection.

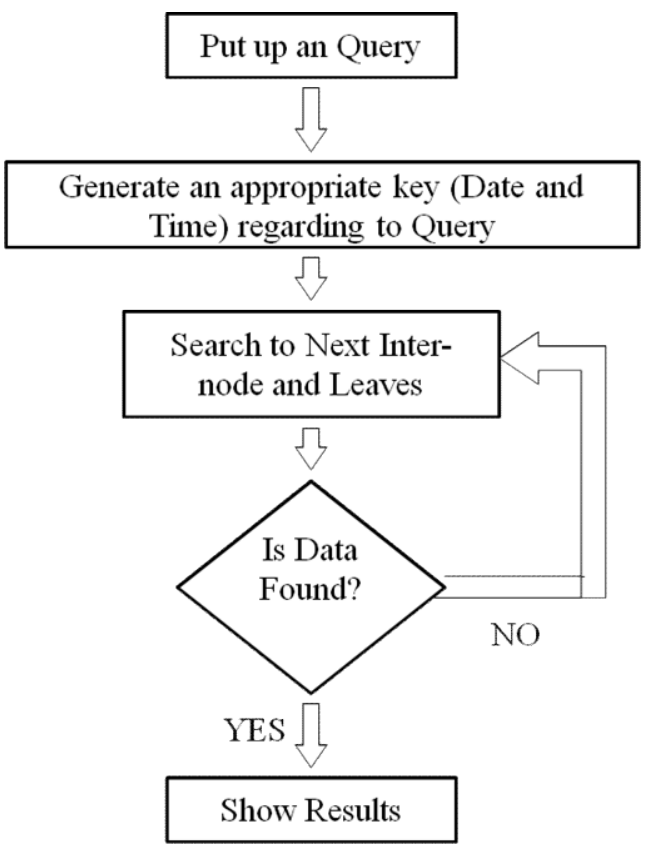

Fig.5- Flowchart of B-Tree working

For any request submitted by us, algorithm generates appropriate key. This key is nothing but the date and time of that particular request. At root node, date of key is searched within available data base. Each date available in database is crosschecked with key date. If date is not matched then search is again continued on next inter-node and leaves. When key is matched, then all time instances at that date are matched with key time. As both date and time of key gets matched with query, data recorded at particular time instance is available for GUI. This data is stored at leaves of tree structure. When algorithm gets exact data matched with key then results are displayed else, key is searched into next inter-node and leaves [14].

Time complexity of B Tree and Red Black Tree is same and small. Time complexity is a time requires for finding a particular data in data base[15,16]. Genetic Algorithm needs much time to access huge data sets i.e. has high time complexity. So, performance of B Tree and Red Black Tree is much better than others. In Genetic Algorithm, we need to find fitness, results comparison. Due to this code complexity of Genetic Algorithm is higher [12].

Also, B tree has better performance for secondary storage devices or flash storage devices. We are providing input data to system in form of pen drive. Due to this also time required to fetch data is reduced. After researches, it has 
been found that B tree does very good for huge data bases. Cloud computing system constructed using B Tree is capable to handle data base of Amazon. These experimental results are very good comparing to others. When we store data of a vehicle for long duration, our data will also become such large [13].

\section{WORKING OF SYSTEM}

This Evidence Collection System plays an important role in collection of evidences for car crash analysis. Initially we provide input excel file that contains data of EDR as shown in Fig.6.

\begin{tabular}{|c|c|c|c|c|c|c|c|c|c|c|c|c|c|c|}
\hline 4 & A & B & C & D & E & $\mathrm{F}$ & 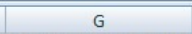 & $\mathrm{H}$ & 1 & J & K & $\overline{\mathrm{L}}$ & M & $\mathrm{N}$ \\
\hline 1 & Date & Time & $\begin{array}{l}\text { TEMPERATURE } \\
\text { (Degree C) }\end{array}$ & $\begin{array}{l}\text { DISTANCE } \\
\text { (feet) }\end{array}$ & SPEED (kmph) & $\begin{array}{l}\text { IMPACT } \\
\text { (KPa) }\end{array}$ & BRAKE PRESSURE(PSI) & $\begin{array}{l}\text { TYRE PRESSURE } \\
\text { (KPa) }\end{array}$ & $\begin{array}{c}\text { Engine } \\
\operatorname{RPM}\left({ }^{*} 10\right)\end{array}$ & LATTITUDE & LONGITUDE & $\begin{array}{l}\text { Alcohol } \\
(\mathrm{mg} / \mathrm{ml})\end{array}$ & SEAT BELT WORE & AIRBAG \\
\hline 2 & $11 / 02 / 2016$ & $10: 23: 06$ & 36 & 11 & 0 & 0 & 0 & 238 & 80 & 21.142790 & 79.093323 & 18 & YES & NOT OPEN \\
\hline 3 & $11 / 02 / 2016$ & 10:23:09 & 36 & 10 & 5 & 0 & 0 & 239 & 80 & 21.142683 & 79.093011 & 18 & YES & NOT OPEN \\
\hline 4 & $11 / 02 / 2016$ & 10:23:12 & 36 & 13 & 20 & 0 & 0 & 240 & 100 & 21.142576 & 79.092699 & 18 & YES & NOT OPEN \\
\hline 5 & $11 / 02 / 2016$ & 10:23:15 & 36 & 7 & 30 & 0 & 0 & 242 & 150 & 21.142468 & 79.092387 & 18 & YES & NOT OPEN \\
\hline 6 & $11 / 02 / 2016$ & $10: 23: 18$ & 37 & 10 & 41 & 0 & 0 & 242 & 180 & 21.142361 & 79.092074 & 18 & YES & NOT OPEN \\
\hline 7 & $11 / 02 / 2016$ & 10:23:21 & 37 & 14 & 48 & 0 & 0 & 242 & 110 & 21.142254 & 79.091762 & 18 & YES & NOT OPEN \\
\hline 8 & $11 / 02 / 2016$ & $10: 23: 24$ & 37 & 11 & 54 & 0 & 0 & 242 & 128 & 21.142147 & 79.091450 & 18 & YES & NOT OPEN \\
\hline 9 & $11 / 02 / 2016$ & $10: 23: 27$ & 37 & 9 & 56 & 0 & 0 & 242 & 140 & 21.142040 & 79.091138 & 18 & YES & NOT OPEN \\
\hline 10 & $11 / 02 / 2016$ & $10: 23: 30$ & 38 & 12 & 61 & 0 & 0 & 242 & 152 & 21.141932 & 79.090826 & 18 & YES & NOT OPEN \\
\hline 11 & $11 / 02 / 2016$ & $10: 23: 33$ & 38 & 14 & 65 & 0 & 10 & 242 & 163 & 21.141825 & 79.090514 & 18 & YES & NOT OPEN \\
\hline 12 & $11 / 02 / 2016$ & 10:23:36 & 38 & 8 & 59 & 0 & 0 & 242 & 148 & 21.141718 & 79.090202 & 18 & YES & NOT OPEN \\
\hline 13 & $11 / 02 / 2016$ & 10:23:39 & 39 & 13 & 61 & 0 & 9 & 242 & 152 & 21.141611 & 79.089890 & 18 & YES & NOT OPEN \\
\hline 14 & $11 / 02 / 2016$ & $10: 23: 42$ & 39 & 9 & 58 & 0 & 10 & 242 & 145 & 21.141504 & 79.089577 & 18 & YES & NOT OPEN \\
\hline 15 & $11 / 02 / 2016$ & 10:23:45 & 39 & 12 & 52 & 0 & 4 & 242 & 120 & 21.141396 & 79.089265 & 18 & YES & NOT OPEN \\
\hline 16 & $11 / 02 / 2016$ & 10:23:48 & 40 & 15 & 50 & 0 & 0 & 242 & 110 & 21.141289 & 79.088953 & 18 & YES & NOT OPEN \\
\hline 17 & $11 / 02 / 2016$ & 10:23:51 & 40 & 18 & 55 & 0 & 18 & 242 & 130 & 21.141182 & 79.088641 & 18 & YES & NOT OPEN \\
\hline 18 & $11 / 02 / 2016$ & $10: 23: 54$ & 41 & 21 & 30 & 0 & 0 & 242 & 150 & 21.141075 & 79.088329 & 18 & YES & NOT OPEN \\
\hline 19 & $11 / 02 / 2016$ & $10: 23: 57$ & 41 & 10 & 38 & 0 & 0 & 242 & 178 & 21.140968 & 79.088017 & 18 & YES & NOT OPEN \\
\hline 20 & $11 / 02 / 2016$ & $10: 24: 00$ & 42 & 14 & 45 & 0 & 0 & 242 & 200 & 21.140860 & 79.087705 & 18 & YES & NOT OPEN \\
\hline 21 & $11 / 02 / 2016$ & 10:24:03 & 42 & 11 & 50 & 0 & 0 & 242 & 110 & 21.140753 & 79.087393 & 18 & YES & NOT OPEN \\
\hline 22 & $11 / 02 / 2016$ & $10: 24: 06$ & 43 & 9 & 52 & 0 & 0 & 242 & 120 & 21.140646 & 79.087080 & 18 & YES & NOT OPEN \\
\hline 23 & $11 / 02 / 2016$ & 10:24:09 & 43 & 10 & 53 & 0 & 0 & 242 & 125 & 21.140539 & 79.086768 & 18 & YES & NOT OPEN \\
\hline
\end{tabular}

Fig.6- Input data received from Event data recorder

When we provide excel sheet like this, as input then this file is gets uploaded in GUI. This is because to reduce time while satisfying the query. After data getting updated we got 3 options.

Search: Here we provide date and time on which we want to analyze performance of vehicle. From data of that time we could get graph of various parameters like Speed Vs Time, Engine Temperature (Degree Celsius) Vs Time, Applied Brake Pressure Vs Time, Distance (Feet) Vs Time, Engine RPM Vs Time etc. Also there is option of plotting all graphs in a single one. From these results graphical comparison of data is possible. If we give a date or Time, which is outside of data base, system will take initial 20 readings of data base and will plot them.

Check Accident: By this function we can find out point where accident has been took place. Automatically system detects that instance and gives detailed information about it. System generates message with cause of accident and values of other sensors. This message contains Speed of vehicle, Distance at that time, Engine temperature, location in form of latitude and longitude, Engine speed in RPM, Alcohol content of driver, Airbag deployment, Seat belt Condition etc. If no any accident happened in data base, message of No Accident Detected will be shown there.

Driver Behavior: Here we have set a threshold value of 100 $\mathrm{kmph}$. Whenever driver drives vehicle equal to this or more than this speed, that time instance will be shown on GUI. Then we need to put up a date and time from extracted data base. By this, graph of points will be plotted showing time intervals on $\mathrm{x}$ axis.

\section{RESULTS}

Fig. 7 is first window when we open GUI. Title of project "Evidence Collection System" is written here. Two buttons are provided here:

Select File: This allows us to select file from Pen drive which we want to analyze. Condition is that, this file must be of Excel type of any size. As, when file size increases, time require for uploading file must also increase.

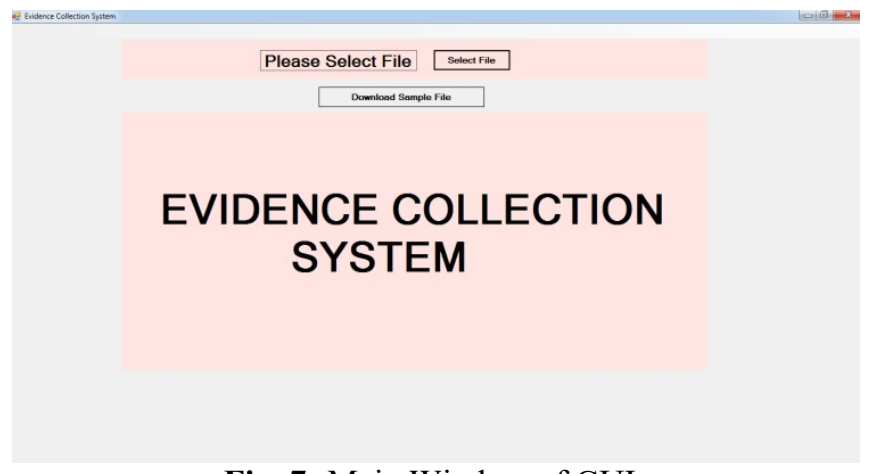

Fig. 7- Main Window of GUI

Download sample File: Sometimes user may be new to system. If he/she doesn't know what is format of input Excel file, then this sample format will help. Position of different columns, time format etc is mentioned in it. 


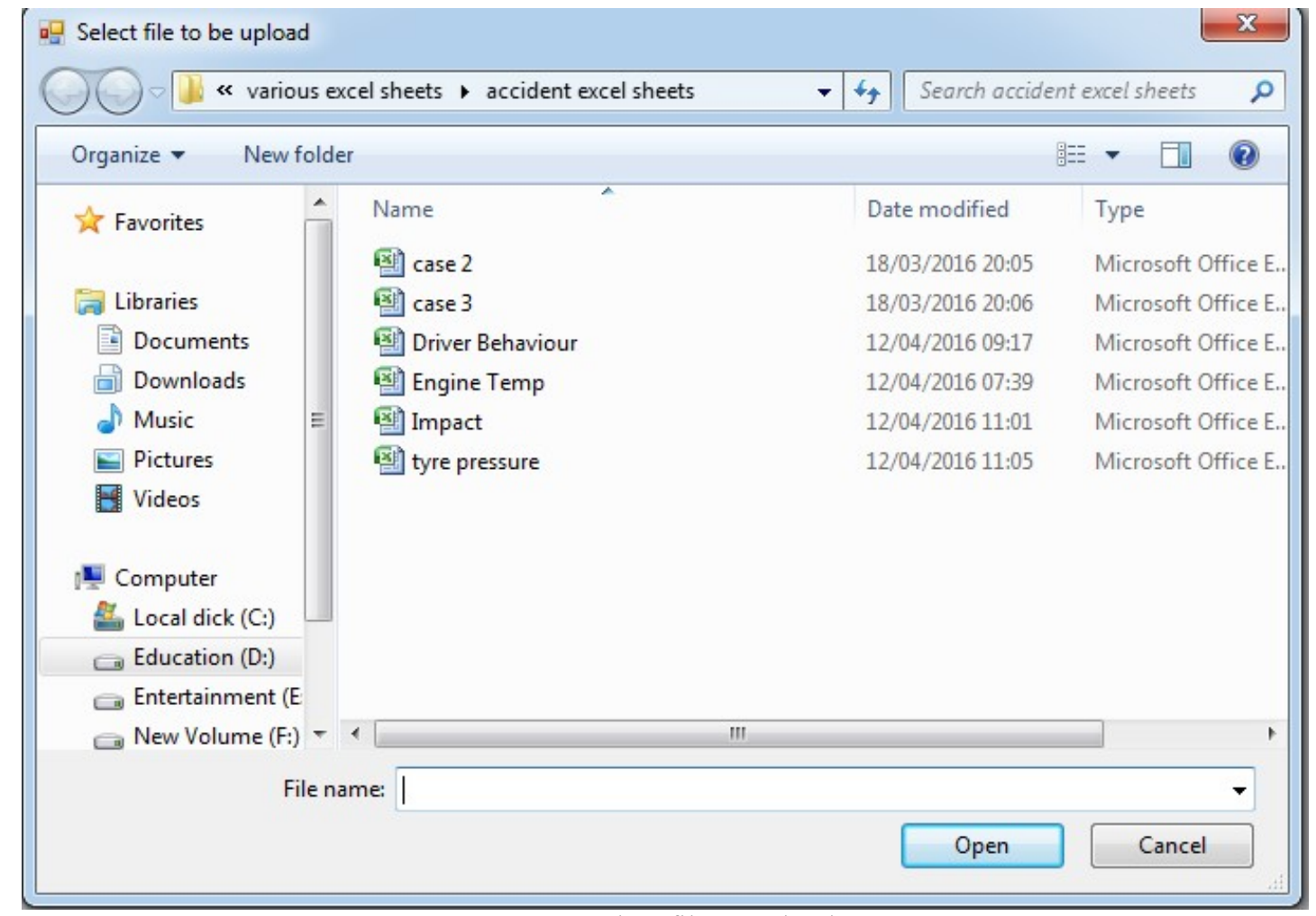

Fig. 8- Select file to upload

When we choose on select file, this window opens. We can access any location of computer to choose file. After selecting file we just need to press "open" button. This is shown in fig. 8 .

\begin{tabular}{|c|c|c|c|c|c|c|c|c|c|}
\hline \multicolumn{6}{|c|}{ 吅 ViewData } & \multicolumn{4}{|c|}{\begin{tabular}{|l|l|l|}
$口$ & 回 & $x$ \\
\end{tabular}} \\
\hline & $\mathrm{F} 1$ & F2 & F3 & $\mathrm{F} 4$ & F5 & F6 & F7 & F8 & $A$ \\
\hline \multirow[t]{18}{*}{ 十 } & Date & Time & TEMPERATURE... & DISTANCE(feet) & SPEED(kmph) & IMPACT(KPa) & BRAKE PRESSU... & TYRE PRESSU... & - \\
\hline & $11 / 02 / 2016$ & $20: 48: 18$ & 63 & 11 & 10 & 0 & 0 & 238 & \\
\hline & $11 / 02 / 2016$ & $20: 48: 21$ & 63 & 10 & 10 & 0 & 0 & 238 & \\
\hline & $11 / 02 / 2016$ & $20: 48: 24$ & 65 & 13 & 20 & 0 & 0 & 238 & \\
\hline & $11 / 02 / 2016$ & $20: 48: 27$ & 67 & 7 & 18 & 0 & 0 & 238 & \\
\hline & $11 / 02 / 2016$ & $20: 48: 30$ & 69 & 10 & 25 & 0 & 0 & 238 & \\
\hline & $11 / 02 / 2016$ & $20: 48: 33$ & 69 & 14 & 32 & 0 & 0 & 238 & \\
\hline & $11 / 02 / 2016$ & $20: 48: 36$ & 73 & 11 & 36 & 0 & 0 & 238 & \\
\hline & $11 / 02 / 2016$ & 20:48:39 & 74 & 9 & 44 & 0 & 2 & 239 & \\
\hline & $11 / 02 / 2016$ & 20:48:42 & 78 & 12 & 40 & 0 & 0 & 239 & \\
\hline & $11 / 02 / 2016$ & 20:48:45 & 81 & 14 & 50 & 0 & 0 & 239 & \\
\hline & $11 / 02 / 2016$ & 20:48:48 & 81 & 8 & 50 & 0 & 0 & 239 & \\
\hline & $11 / 02 / 2016$ & $20: 48: 51$ & 82 & 13 & 50 & 0 & 0 & 239 & \\
\hline & $11 / 02 / 2016$ & $20: 48: 54$ & 82 & 9 & 58 & 0 & 3 & 239 & \\
\hline & $11 / 02 / 2016$ & $20: 48: 57$ & 85 & 12 & 53 & 0 & 3 & 240 & \\
\hline & $11 / 02 / 2016$ & 20:49:00 & 85 & 15 & 47 & 0 & 0 & 240 & \\
\hline & $11 / 02 / 2016$ & 20:49:03 & 87 & 18 & 53 & 0 & 0 & 240 & \\
\hline & $11 / 02 / 2016$ & 20:49:06 & 87 & 21 & 59 & 0 & 0 & 240 & - \\
\hline \multirow[t]{2}{*}{1} & \multicolumn{4}{|c|}{ I"I } & \multicolumn{4}{|c|}{1} & \\
\hline & Search & \multicolumn{2}{|c|}{ Check Accident } & Driver Behaviour & & & & & \\
\hline
\end{tabular}

Fig 9-File uploaded in GUI

The above figure 9 shows uploaded data from secondary storage device. This is EDR's data recorded while vehicle was running. Here again we got three choices. Search,
Check Accident and Driver Behaviour. When we select Search, following dialog box opens as shown in fig. 10 . 


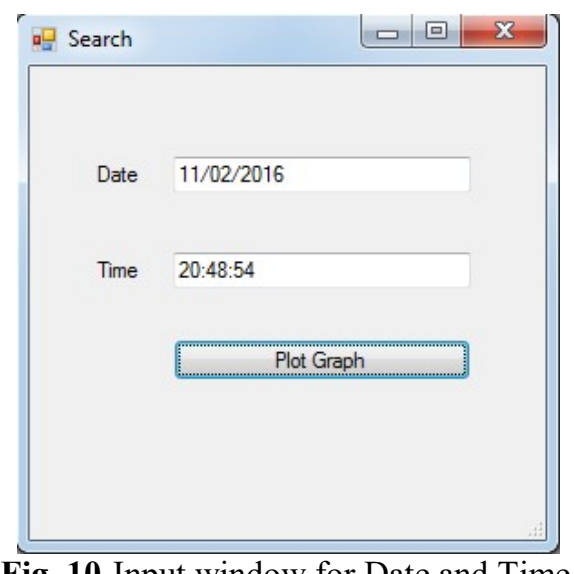

Fig. 10-Input window for Date and Time

But, if we provide Date or Time which is not in database, Message of Data not available will be displayed. shown in fig 11.

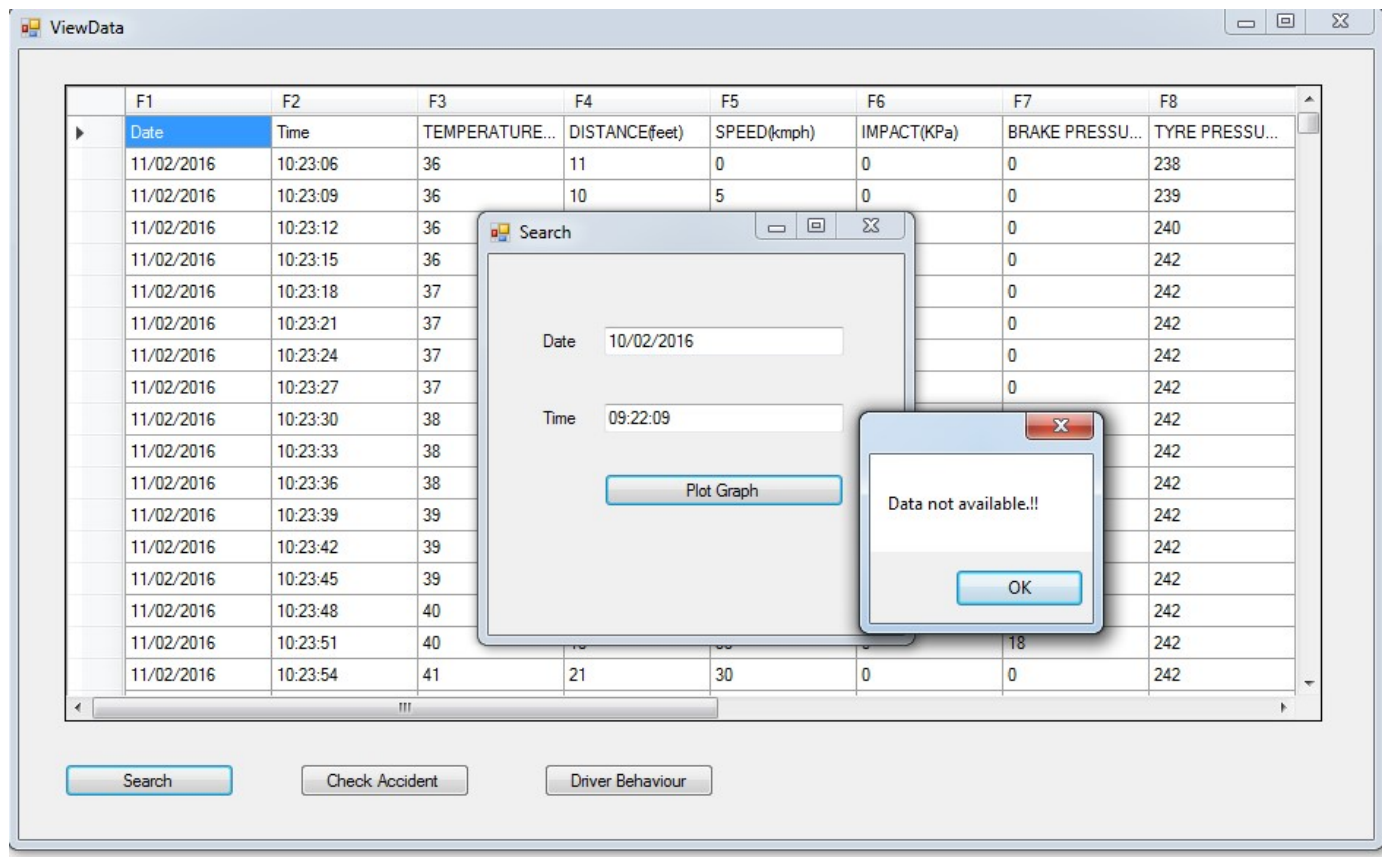

Fig. 11- Message for Date/Time outside Database

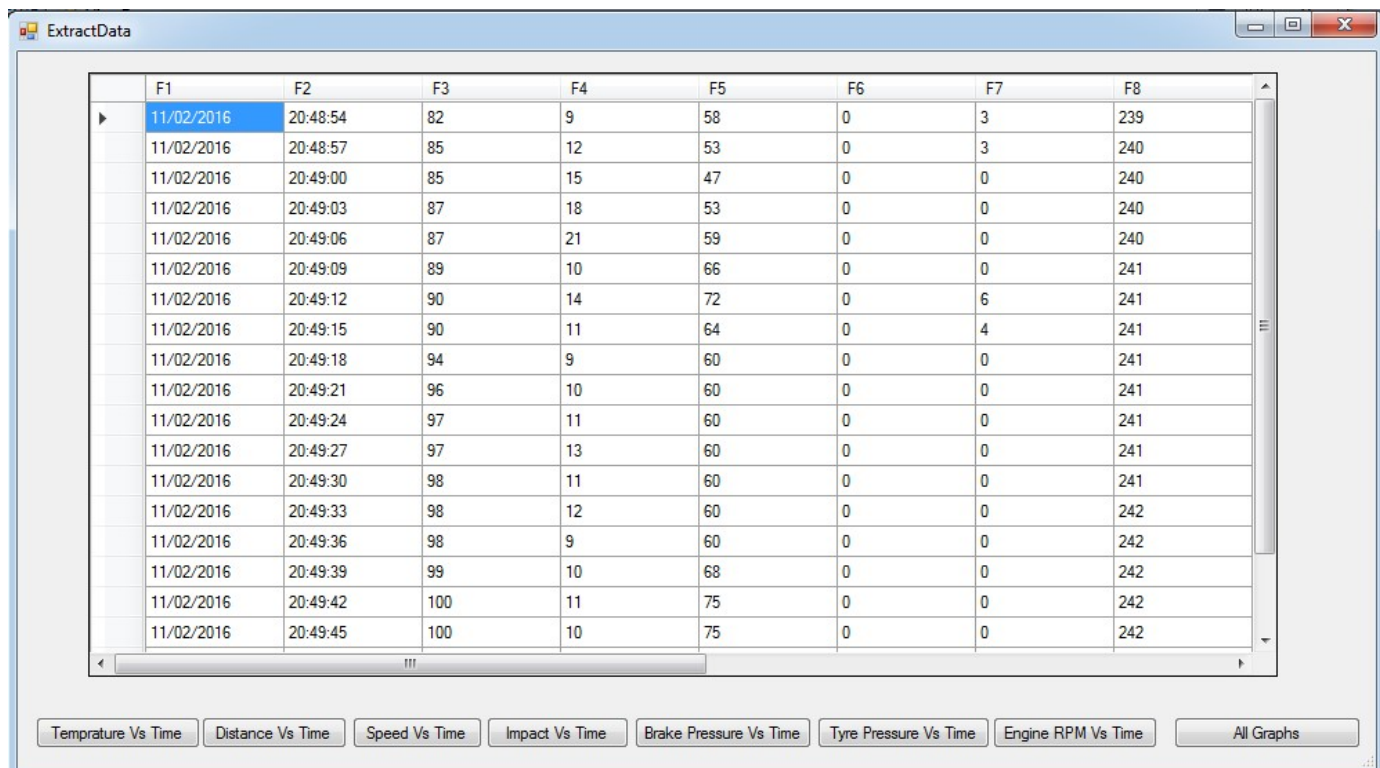

Fig. 12-Data of particular Date and Time 
When user puts date \& time and click for plot graph, window with next 20 recording opens. Here we have options of graph of Speed, Distance, Engine Temperature, Impact, Brake pressure, Tire pressure, Engine speed etc. with respect to time. As shown in fig-12.
Also, we can plot all of these graphs in a single window. Each of these graphs is shown in fig-13.

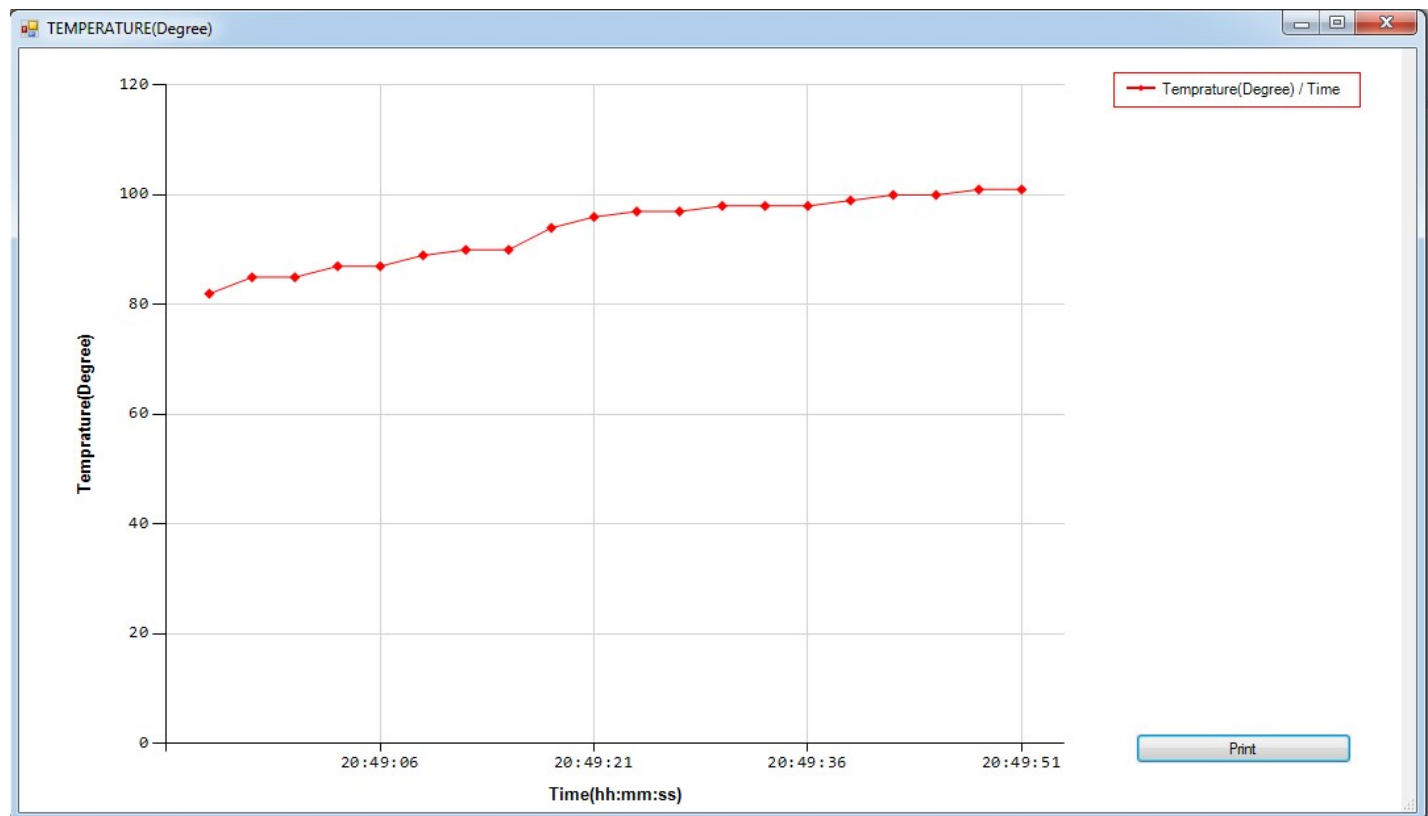

Fig. 13-Graph of Engine Temperature Vs Time

This graph (fig-13) shows variation in Engine Temperature regarding to time. This Engine Temperature is in Degree Celsius. This data is recorded when vehicle was just started. Due to this it shows variation in temperature. Otherwise, this graph will be constant. There are some cases where due to car burning, accident has been happened. That's why this parameter is included in Event data recorder.

By accessing data of engine temperature, vehicle manufacturing companies will make changes in their engine performance, engine coolant. These results will help to improve performance of engine and engines will not get too hot while driving.

Sufficient distance must be maintained between our vehicle and front vehicle. This graph shows distance in feet from our vehicle and next vehicle. This distance is in feet. By this graph we can find, did driver maintain sufficient distance or not? Minimum value in graph shows that, driver was about to collide on front vehicle. As shown in fig-14.

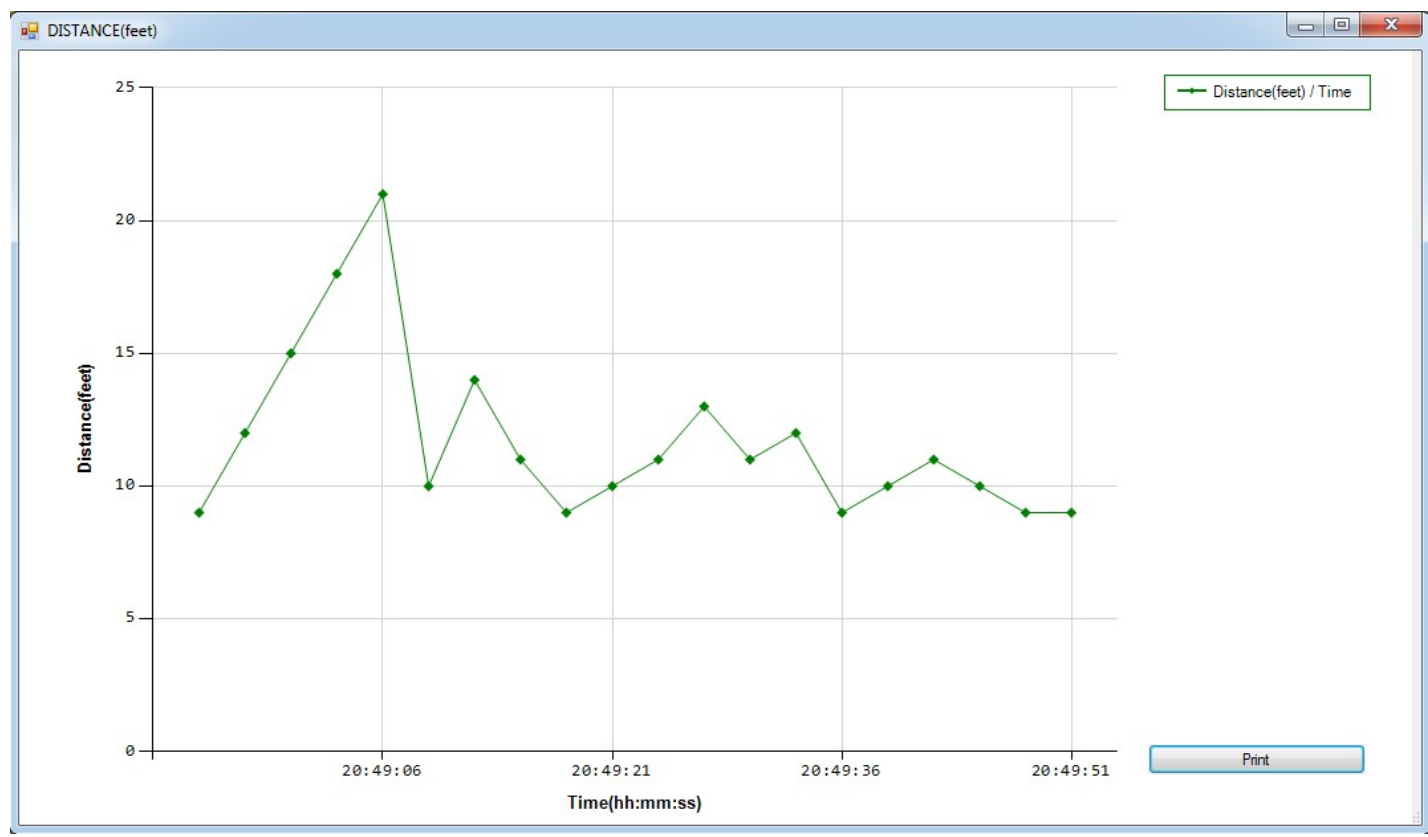

Fig. 14-Graph of Distance Vs Time 
This graph shows Speed of vehicle with respect to time. If driver drives vehicle roughly, this graph will be zig-zag.
Result of this graph can be used in Driving License Issuing cases. As shown in fig 15.

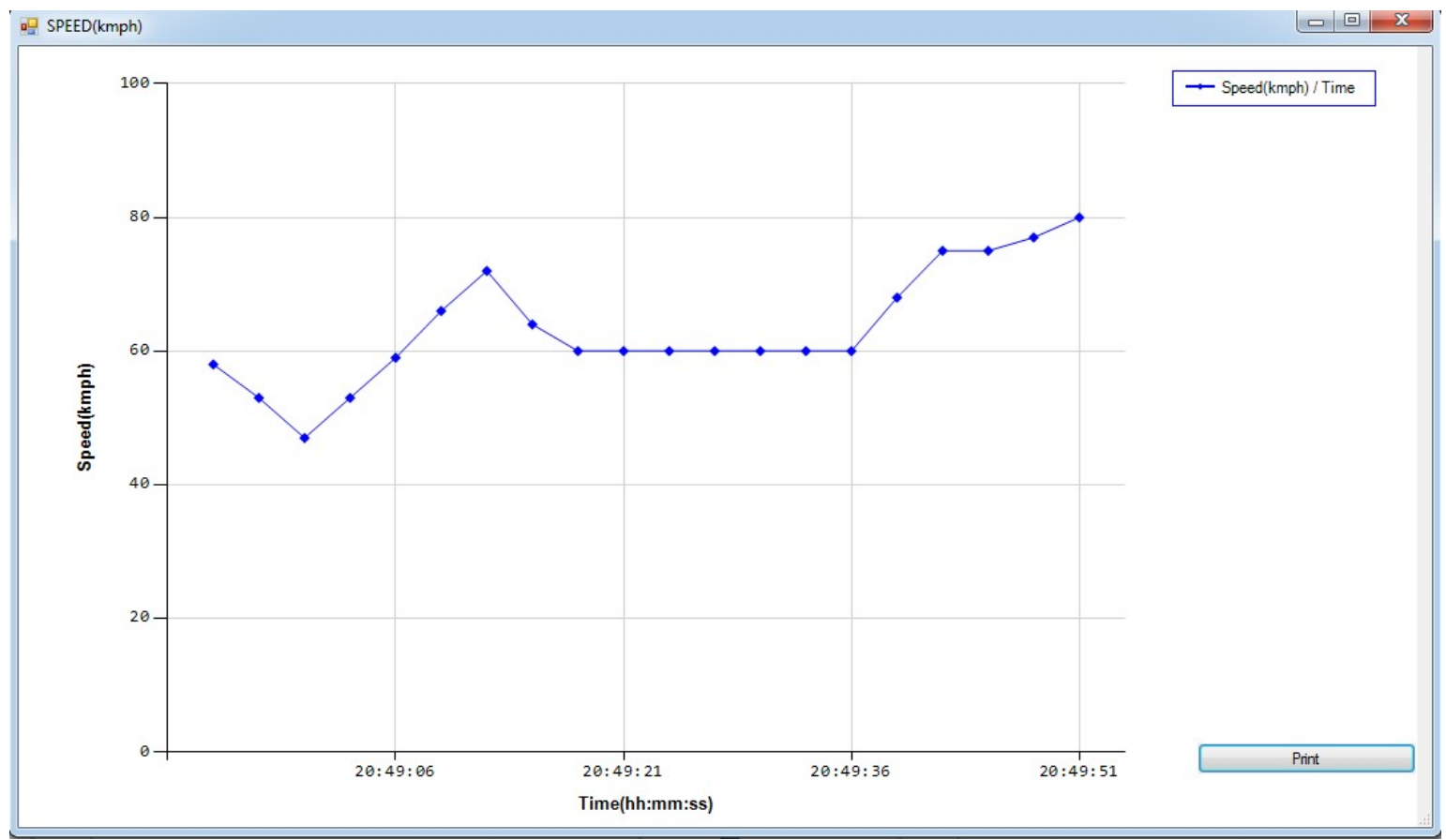

Fig. 15-Graph of Speed Vs Time

This shows in fig. 16, when driver had applied brake to vehicle. By quantity of applied pressure, severity of Brake will be determined. We categorize this in hard brake or soft brake.

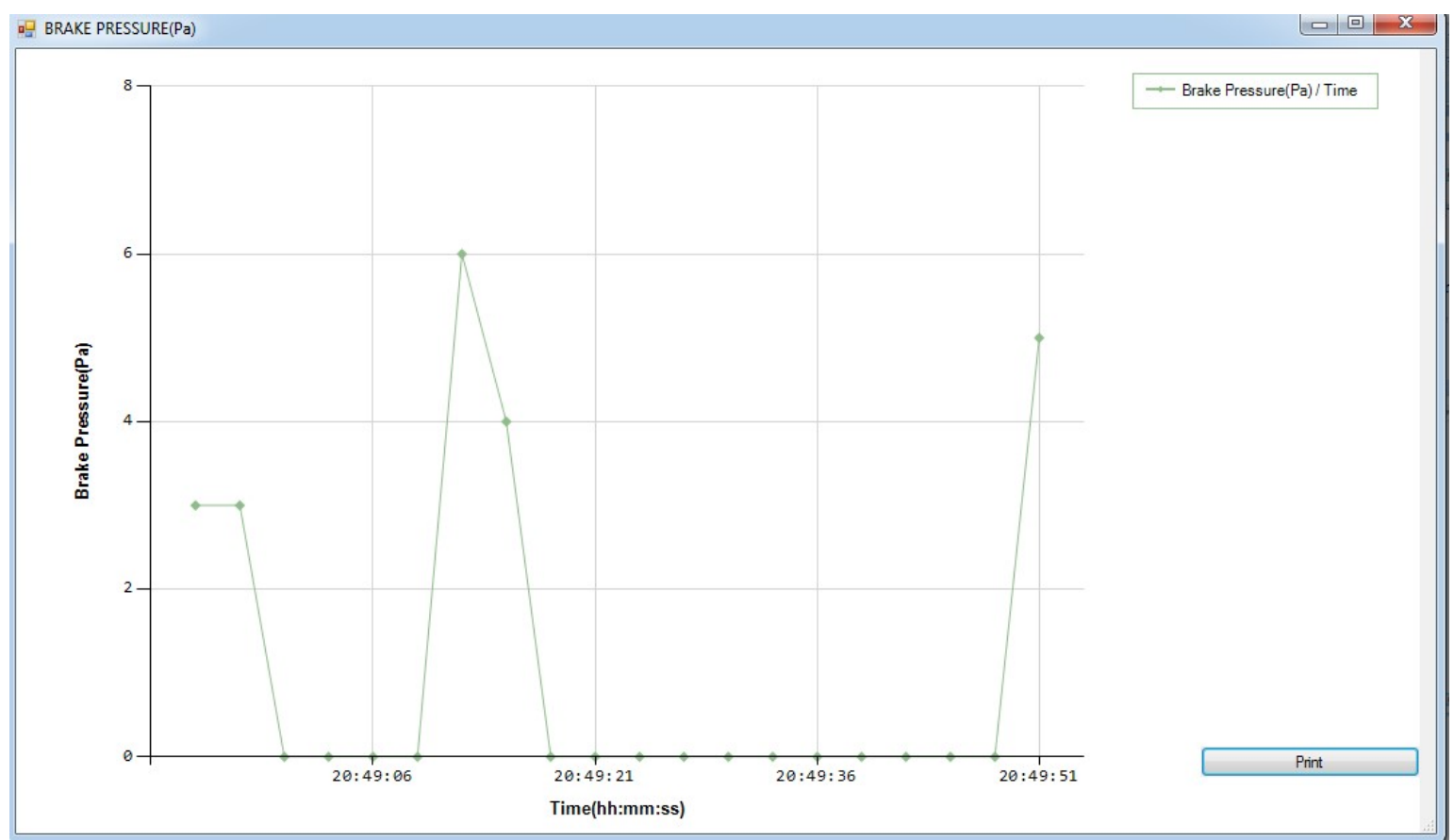

Fig. 16-Graph of Brake Pressure Vs Time

Fig. 17.graph shows actual tire pressure with respect to time. Normally tire pressure range varies between 230 to 270 $\mathrm{KPa}$. Tire gets burst at $300 \mathrm{KPa}$. This will collect information regarding to highest tire pressure in any of the tire. So, if accident happened due to tire burst, we could get evidence of tire burst and exact tire pressure before accident. 


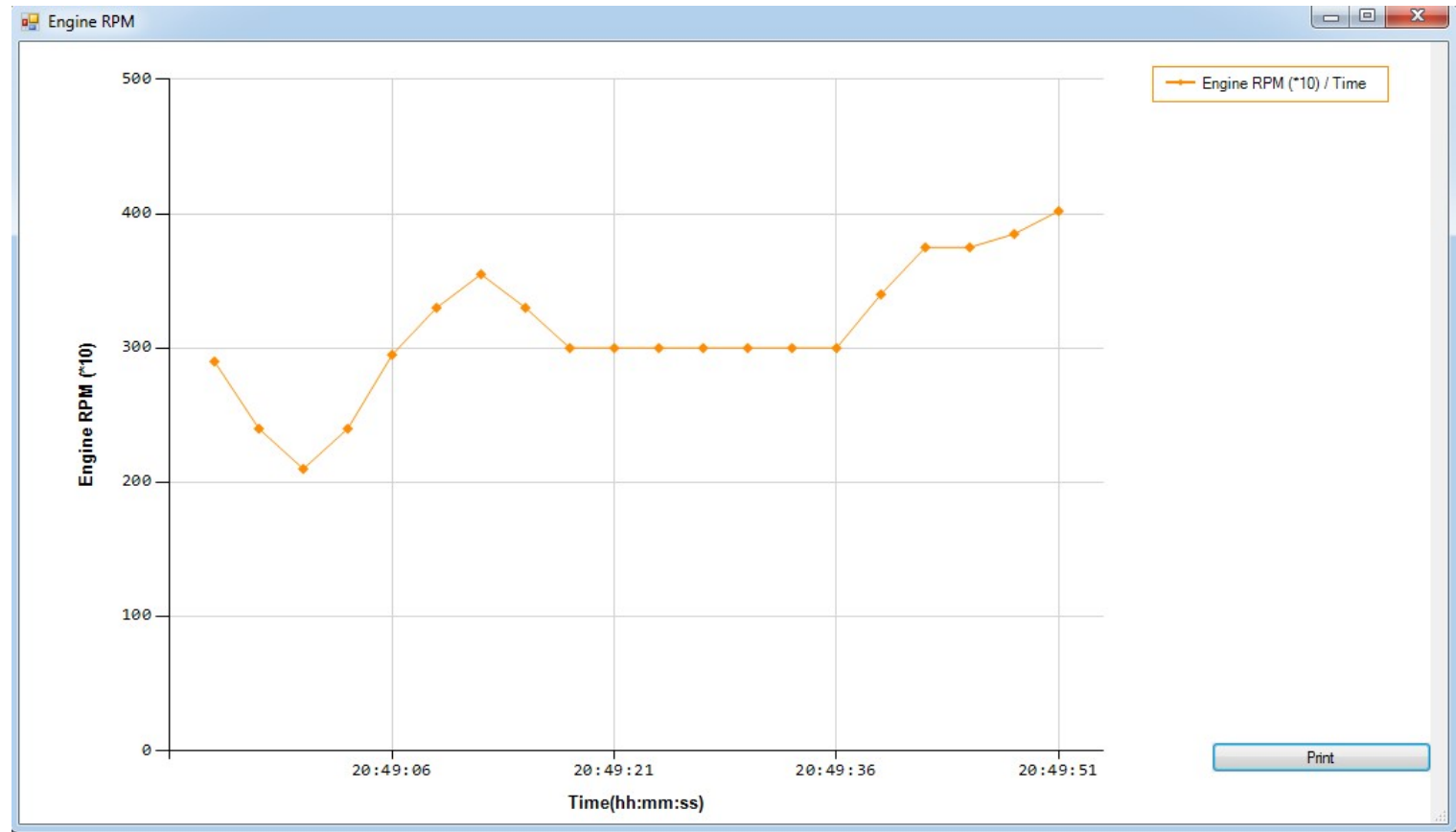

Fig. 17-Graph of Engine Speed (RPM) Vs Time

Fig. 17 shows-Graph of Engine Speed Vs Time gives information about change in Engine Speed. This is useful in case to find speed is due to Acceleration or slope of road

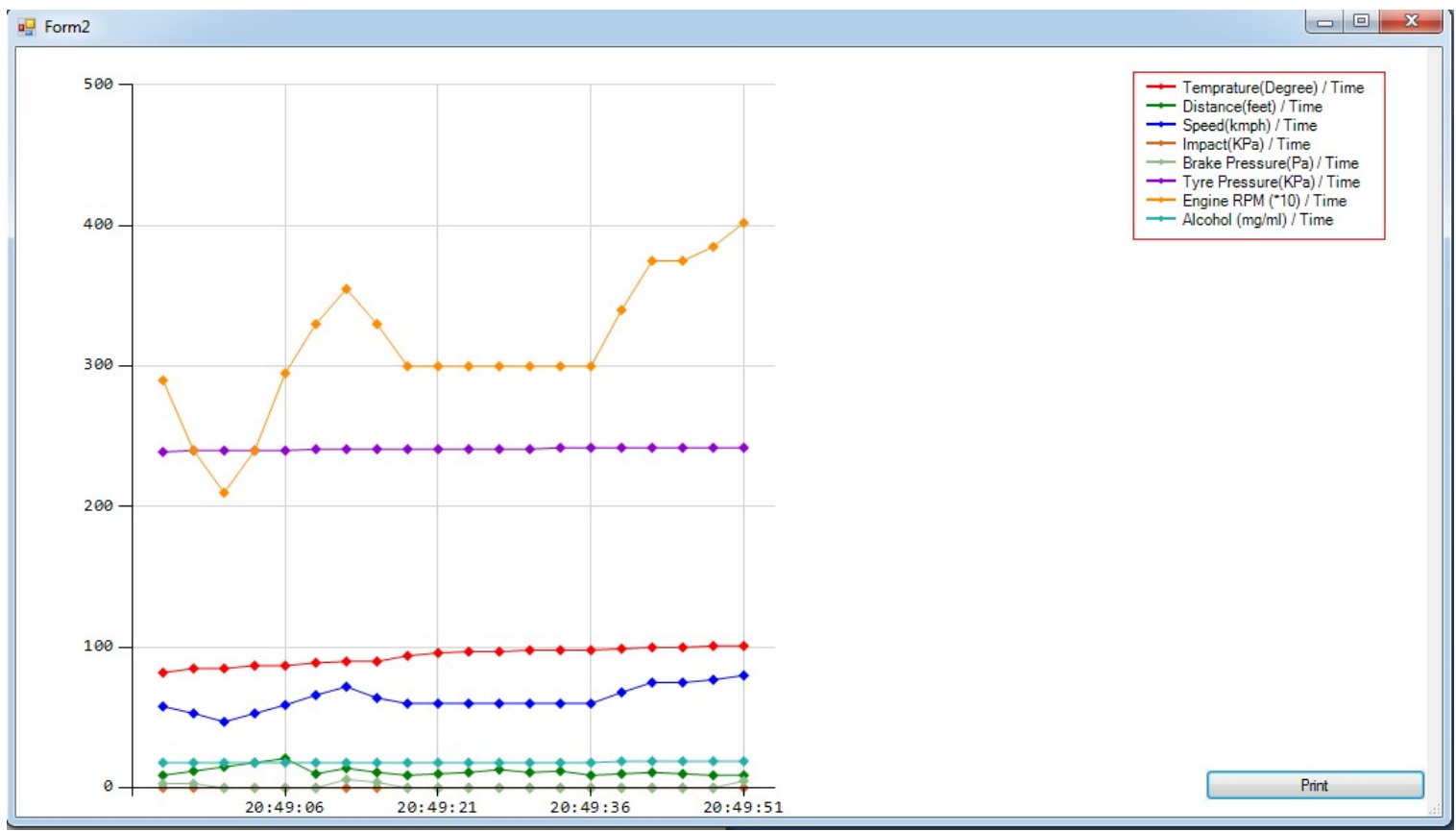

Fig. 18-All Graphs Vs Time

Above figure 18 shows merge graph. All graphs can be seen within this single one. If one want to overlook all readings in single view, this graph is helpful.

\section{DRIVER BEHAVIOR MODEL}

This button in GUI helps to see performance of driver in speed. By clicking on this button, we get date and time at which driver increased speed more than threshold. Here we have set threshold of $100 \mathrm{KMPH}$. It is shown in Fig-19.
All points in data base where driver crossed speed limit are shown here. As, all of them couldn't be plot on a single graph, we must provide date $\&$ time to plot graph. 20 entries next to provided time are plotted on a graph. If we give Date / Time which is not included in table or database, then message of "Data Not Available" will be displayed as shown in fig-20. 


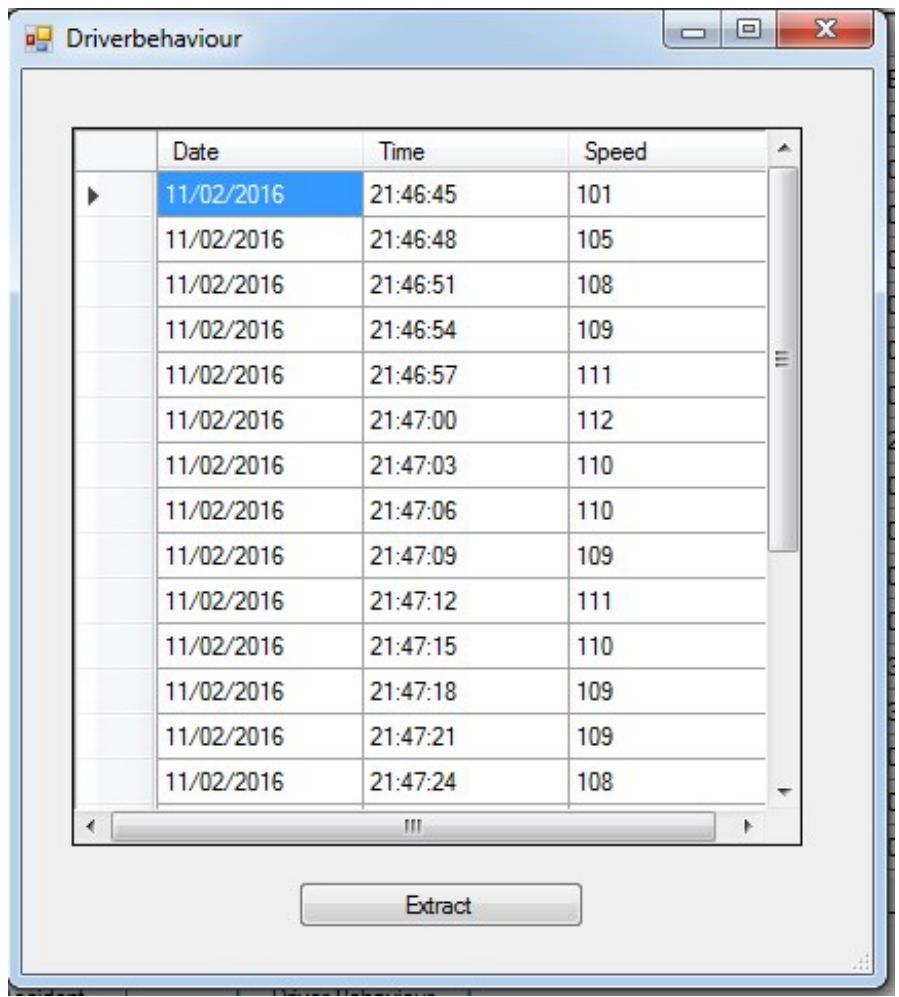

Fig. 19-Date and Time where driver crossed speed limit

As shown in fig-20 performance of driver, this data can be used at different cases. Driving license issuing authorities, Transport company owner, Insurance Issuing agents are beneficial from this data.

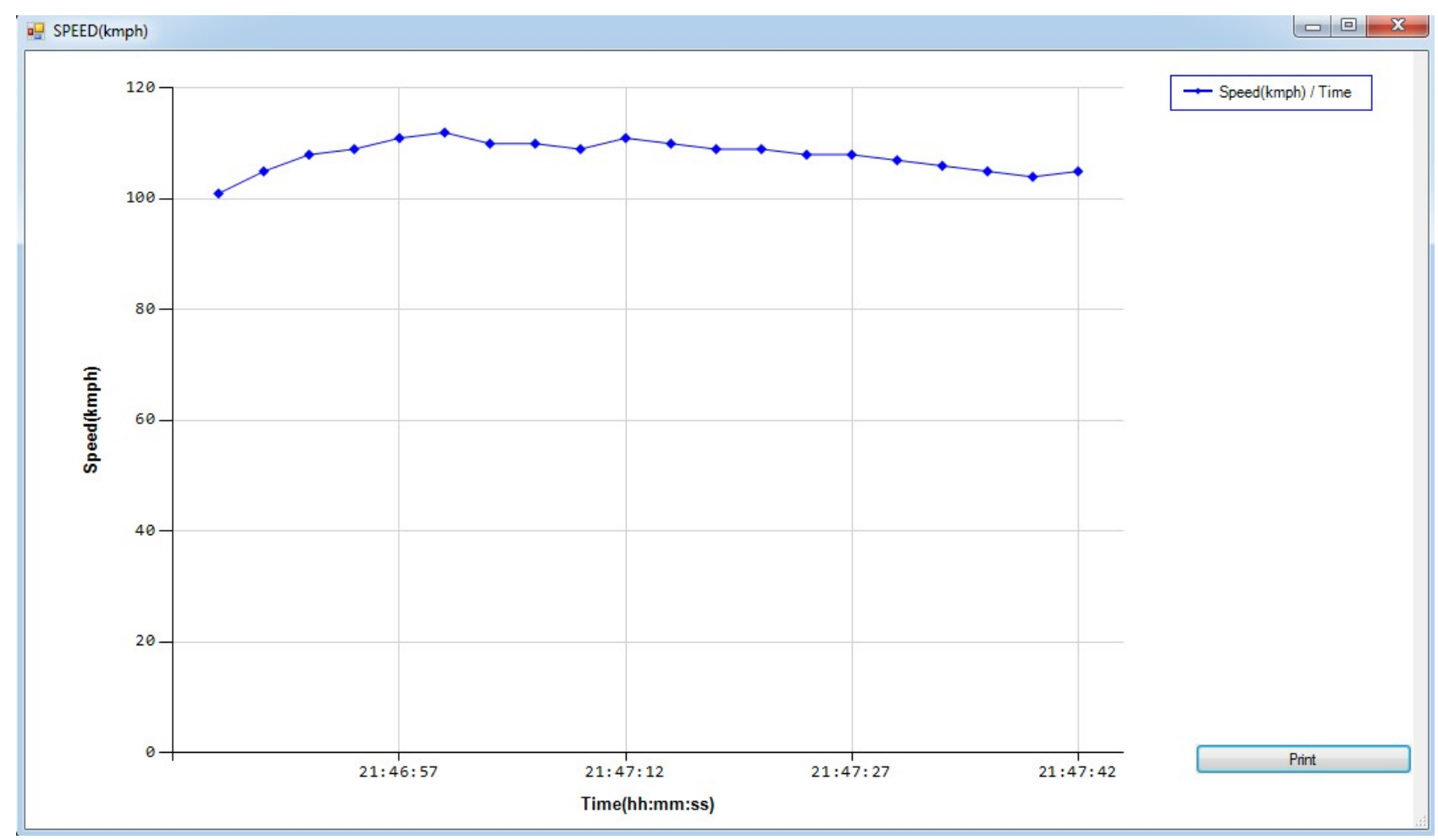

Fig. 20-Driver Behavior Model

Check for accident button in GUI allows detecting accident in data base. 


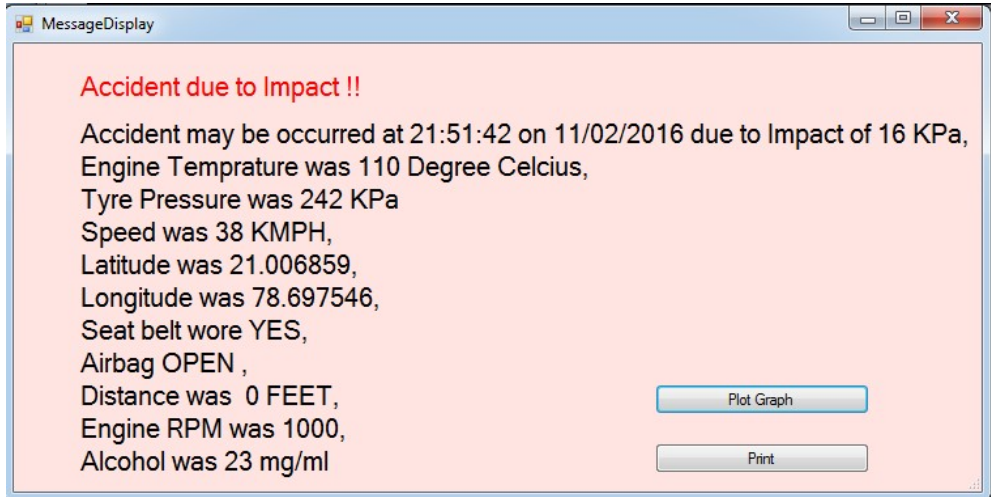

Fig. 21-Accident due to Impact case

Here, main reason of accident is highlighted by using red colour. Readings of all other parameters at that time are also mentioned in message.

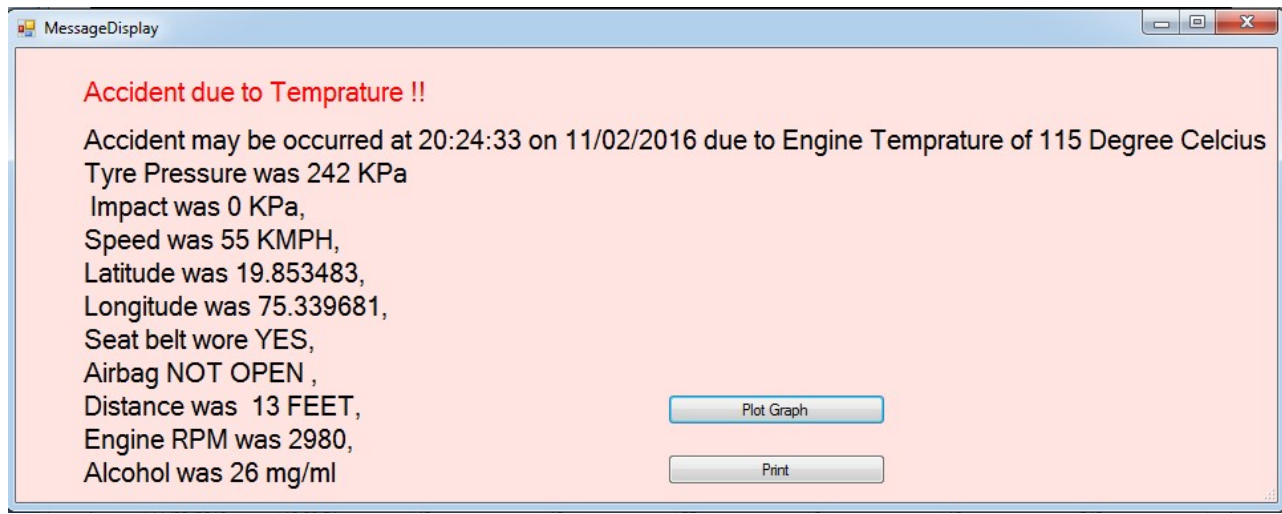

Fig. 22-Accident due to High Engine Temperature case

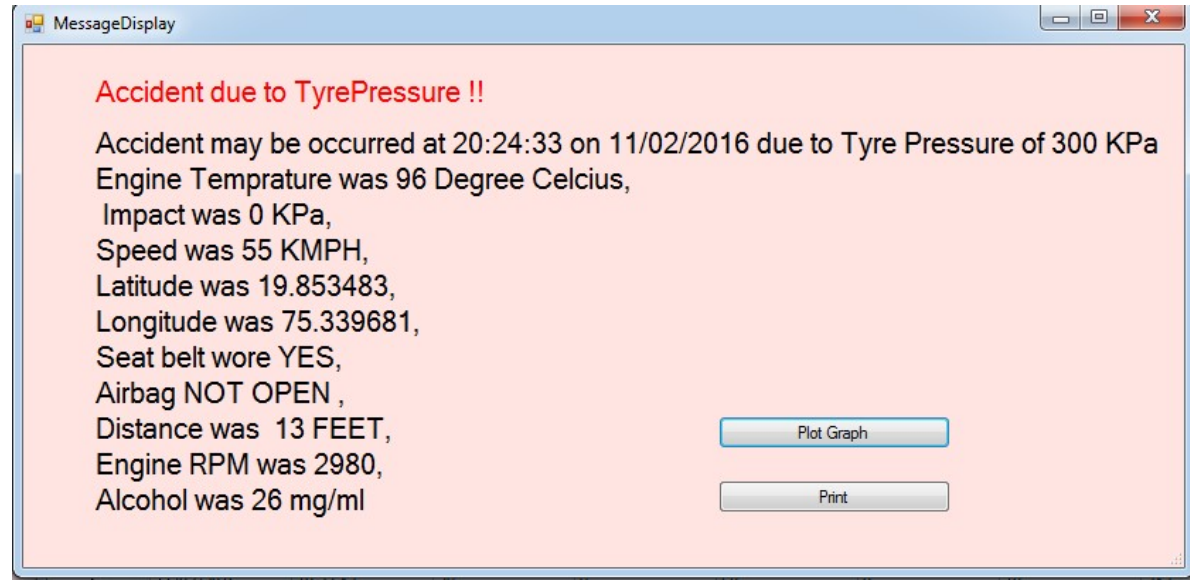

Fig. 23-Accident due to Tire Burst case

From this data, accident may be happen due to either High Engine Temperature (fig-22), Tire Burst (fig-23) or Crash (fig-21). So, we have set 3 thresholds here. Whenever recorded data crossed any of limit accident got detected.

\section{CONCLUSION}

This paper deals with collection of Evidences for car crash analysis. It works on data collected by Event Data Recorder. This data must contain speed of vehicle (kmph), Date (dd/mm/yyyy), Time (hh:mm:ss), Distance (Feet), Engine
Temperature (Degree Celsius), Tire Pressure (KPa), Impact (KPa), Position (Latitude and Longitude), Seat Belt, Airbag Deployment, Engine Speed (RPM), Alcohol Content $(\mathrm{mg} / \mathrm{ml})$. As results of Excel are better in case of memory requirement, input file must be in form Excel sheet.

This system is developed using B-tree algorithm for data analysis purpose. B-tree found much efficient as its performance is good for secondary storage devices and it can handle data base of large size. 
This system based on GUI, which is constructed using Microsoft Visual Studio. This GUI can create various graphs like Graph of Speed Vs Time, Distance Vs Time, Engine Temperature Vs Time, Brake Pressure Vs Time, Tire Pressure Vs Time and Engine speed (RPM) Vs Time at any time instance of database. A single graph with all of these graphs merged can also be plotted.

System can check for accident within database. If any accident happens in database, system will display message containing cause of accident and readings of all other sensors at that time. Driver Behavior Model will help to find performance of driver. If he drives by speed more than 100 KMPH graph of that time instances will be plotted.

\section{FUTURE SCOPE}

It is predictable that the very positive effect of the project would inspire additional development in this likely area, thus significant to effective commercial as well as industrial application. The future work is to match system with Event Data Recorder which stores video recording.

\section{REFERENCES}

[1]. Amarnath S. Kale, Prof. P.H. Chandankhede, "Design and Implementation of Evidence Collection System From Event Data Recorder For Car Crash Analysis", International Journal of Recent Trends in Engineering \& Research (IJRTER) Volume 02, Issue 02; February - 2016.

[2]. Amit Lute, Prof. Pankaj H. Chandankhede, Dr. M. M. Khanapurkar, " ARM7 Processor based Event Data Recorder using CAN for Vehicular Systems", IJRTER, Volume 2 Issue 2, February 2016.

[3]. Amarnath S. Kale, Prof. P.H. Chandankhede, "Evidence Collection System From Event Data Recorder For Car Crash Analysis", International Conference on Innovations and Technological Developments in Computer, Electronics and Mechanical Engineering (ICITDCEME-15), 28-29 Dec. 2015.

[4]. Nitin P. Sirsikar, Prof. Pankaj H. Chandankhede, "Design of ARM based Enhanced Event Data Recorder \& Evidence Collecting System”, IOSR-JECE 2014.

[5]. Shital V. Vaidya, Prof. P. H. Chandankhede, "Designing of Event Data Recorder for Vehicle Monitoring based on ARM processor" International Conference "Emerging Trends in Science, Engineering, Business and Disaster Management" ICBDM 2014 , Image Processing and Networking Volume:8 Special Issue IV, Feb 2014, ISSN No:0973-2993.

[6]. B.Pravin Kumar, V. Anuragh, Nlp Raju, "Accelerometer Based Vehicle Monitoring And Tracking System Using ARM Processor And GPS”, International Journal of Science Engineering and Advance Technology, IJSEAT, Volume 2, Issue 11, ISSN 2321-6905 November2014.

[7]. Anoop Mathew, Joseph Kuncheria, Yadukrishnan S, Gifty Raju, Haritha Chandrasekhar, "Car Black Box", International Journal of Innovative Science and Modern Engineering (IJISME) ISSN: 2319-6386, Volume-2 Issue11 , October 2014.
[8]. Mooseop Kim, Chi Yoon Jeong, “An Efficient Data Integrity Scheme for Preventing Falsification of Car Black Box", ICTC pp. 1020-1021, 2013.

[9]. Lei Yu, Ge Fu, Yan Jin, Xiaojia, Xiang, Huaiyuan Tan, Hong Jhang, Xinran Liu, Xiaobo Zhu, "MPDBS: A Multilevel Parallel Database System Based on B-Tree", IEEE SNPD, Takamatsu, Japan. 1-3 June, 2015.

[10]. Sai WU, Dawei Jiang, Beng Chin Ooi, Kun-Lung Wu, "Efficient B-Tree base Indexing for Cloud Data Processing”, pp. 1207- 1214, Proceedings of VLDB Endowment, Volume 3, No. 1, 2010.

[11]. Kangsuk Chae, Chulhwa Hong, Truong Le, Jaeduck Choi \&Souhwan Jung, "Evidence collection from car black box using Smartphone", 8th Annual IEEE consumer Communications and networking Conference, Japan 2011,pp. 851-856.

[12]. Sai WU, Dawei Jiang, Beng Chin Ooi, Kun-Lung Wu, "Efficient B-Tree base Indexing for Cloud Data Processing", pp. 1207- 1214, Proceedings of VLDB Endowment, Volume 3, No. 1, 2010.

[13]. Chin Hsien Wu, Tei Wei Kuo, Li Ping Chang, "An Efficient B-Tree Layer Implementation For Flash-Memory Storage Systems", ACM Transactions On Embedded Computing Systems, Vol. 6, No. 3, Article 19, July 2012.

[14]. Justin J. Levandoski 1, David B. Lomet 2, Sudipta Sengupta, "The Bw-Tree: A B-tree for New Hardware Platforms", ICDE Conference 2013

[15]. Goetz Graefe, Harumi Kuno, "Modern B-tree Techniques", IEEE International Conference on Data Engineering (ICDE), 11-16 April 2011.

[16]. J. E. Hopcraft, J.D.Ullman, A. V. Aho, "Data Structures and Algorithm”, pp. 387, 4th impression 2009.

\section{BIOGRAPHIES}

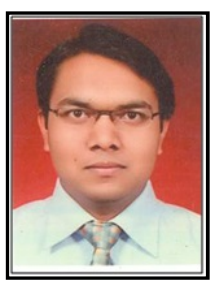

Pankaj Chandankhede is pursuing $\mathrm{Ph} . \mathrm{D}$. in Electronics Engineering Department. He has 7 years of teaching \& research experience with around 16 publications in reputed Journals \& Conferences.

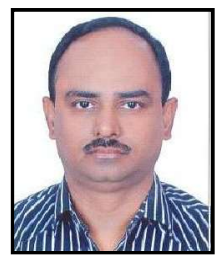

Dr. Milind Khanapurkar is a professor and head of the department of Electronics and Telecommunication Engineering. He has 25 years of teaching and research experience with around 30 research contributions with book chapters. He has one patent on his name with and is recipient of several grants from various funding agencies. 